\title{
uso de plantas medicinais para fins terapêuticos: os conhecimentos etnobotânicos de alunos de escolas pública e privada em Floriano, Piauí, Brasil
}

The medical plants use for therapeutic purposes: the students ethnobotanical knowledge in a public and private school in Floriano, Piauí, Brazil

\section{Resumo}

Ao longo dos anos, a população vem utilizando as plantas medicinais para o tratamento de diversas doenças. Neste sentido, objetivou-se identificar os conhecimentos acerca da utilização de plantas medicinais empregadas para fins terapêuticos entre os alunos da $3^{a}$ série do Ensino Médio de uma escola pública e privada em Floriano/PI, bem como também verificar de que forma esses saberes podem interferir na escolha desse recurso natural. Adotou-se uma pesquisa epistemológica, com abordagem quali-quantitativa, em que aplicou-se um questionário com 100 alunos, sendo 50 da rede pública e 50 da rede privada. Verificou-se que $82 \%$ dos alunos da escola pública e 92\% da escola privada utilizavam as plantas medicinas. Além disso, as famílias das plantas mais citadas pelos alunos de ambas as escolas foram: Lamiaceae, Rutaceae, Verbenaceae e Fabaceae. Alguns alunos não relacionaram as plantas medicinais com problemas ao organismo. A maioria relataram que o chá não causa dano por ser natural e utilizado durante muitas gerações. A parte que eles mais utilizavam eram as folhas e as cascas. Portanto, há necessidade de estudos mais aprofundados com o objetivo de avaliar as principais propriedades biológicas dos espécimes utilizados pelos alunos, a fim de propiciar segurança no consumo dessas plantas.

Palavras-chave: Conhecimento popular; Terapêuticos; Tóxico; Genotóxico; Recurso natural.

\section{Abstract}

Over the years, the population has been using medicinal plants for the treatment of various diseases. This popular knowledge has been handed down from generation to generation as a medicinal alternative based on empirical knowledge. Therefore, this work sought to relate the knowledge about the use of medicinal plants used for therapeutic purposes among high

\footnotetext{
${ }^{1}$ Universidade Federal do Piauí | mauriciosanges11@hotmail.com

2 Instituto Federal do Piauí | michellelima@ifpi.edu.br
} 
school students of a public and private school in Floriano / PI, as well as to verify how these knowledge can interfere in choosing this natural resource. We adopted an epistemological research, with a qualitative-quantitative approach, in which a questionnaire with objective and subjective questions was applied with 100 students, fifty of the public network and fifty of the private network. It was found that $82 \%$ of the public school students and $92 \%$ of the private school used the medicine plants. In addition, the families of the plants most cited by the students of both schools were: Lamiaceae, Rutaceae, Verbenaceae and Fabaceae. Some students did not relate the medicinal plants with problems to the organism. Corroborating with this result, most reported that tea does not cause harm by being natural and used for many generations. The part they used most were the leaves and the bark. Therefore, there is a need for more in-depth studies with the objective of evaluating the main biological properties of the specimens used by the students, in order to provide safety in the consumption of these plants.

Keywords: Popular knowledge; Therapeutics; Toxic; Genotoxic; Natural resource.

\section{Introdução}

A extração de recursos naturais da flora nativa vem sendo observada ao longo da história das civilizações. As plantas medicinais são utilizadas há muitos anos com objetivo terapêutico, principalmente por pessoas com falta de acesso à medicina tradicional (SCHIAVO; SCHWAMBACH; COLET, 2017). Esse processo foi decisivo para o tratamento de diversas doenças ao longo dos tempos e tem contribuído para o fortalecimento da bioprospecção. Essa técnica consiste na seleção de espécies de plantas com finalidade de encontrar compostos bioativos, a fim de serem utilizados posteriormente como um recurso farmacológico pela indústria farmacêutica ou biotecnológica (LIMA et al., 2017).

\section{Conhecimento etnobotânico}

A utilização desses recursos naturais, através da medicina tradicional, está arraigada às manifestações culturais das comunidades. Por isso, muitas vezes, faz-se o uso sem conhecer suas propriedades biológicas (LARANJEIRA et al., 2016). Outro problema enfrentado é a concentração empregada no preparo de soluções extraídas das plantas medicinais. O desconhecimento da concentração correta pode tornar-se um problema a nível celular, devido à exposição das células às substâncias tóxicas, o que pode causar danos no material genético (MELO et al., 2017).

As plantas produzem compostos que são de grande importância para o seu ciclo de vida. Os metabólitos primários são considerados moléculas encontradas nas células vegetais, como aminoácidos, proteínas e os ácidos nucléicos (TAIZ; ZEIGER, 2013). Já os metabólitos secundários são restritos em sua distribuição, apresentam grande importância para a sobrevivência e a propagação para as que os produzem. Alguns funcionam como herbívoros, patógenos ou competidores, sendo estocados principalmente nos vacúolos. Além disso, são divididos em: alcaloides, terpenoides e os compostos fenólicos (EVERT; EICHHORN, 2014).

O conhecimento etnobotânico ao longo dos tempos vem atuando na consolidação das culturas, principalmente através das manifestações do contexto cultural em que estão inseridos e das práticas desenvolvidas. O termo "etnobotânica" foi descrito pela primeira vez 
pelo americano William Harshberger (1869-1929), o qual discute sobre o estudo das relações entre os seres humanos e as plantas em suas diversas dimensões (MACHADO et al., 2017). Assim, o homem vem utilizando empiricamente os conhecimentos construídos através da fitoterapia na escolha de plantas medicinais para tratar determinadas doenças, ou seja, valer-se desses recursos com a finalidade terapêutica (NASCIMENTO et al., 2012).

O conhecimento etnobotânico é relevante para o desenvolvimento humano. Esse entendimento sobre as principais plantas com inestimável valor medicinal pode ser convertido em fármacos, que poderão ser produzidos pelas indústrias farmacêuticas ou biotecnológicas e ajudar a população no tratamento de determinadas doenças (MONTEIRO; BRANDELLI, 2017).

\section{Utilização de fitoterápicos sob uma ótica educacional}

São encontrados nas plantas diversos princípios ativos que podem ser utilizados nas práticas medicamentosas. Os fitoterápicos consistem em medicamentos provenientes de drogas vegetais que apresentam atividades farmacológicas comprovadas (BRASIL, 2004). Em muitos casos, boa parte da população troca os medicamentos sintéticos por fitoterápicos extraídos de plantas devido ao fato de serem considerados menos agressivos e propiciarem o mesmo efeito dos medicamentos, além do fácil acesso pela população (SIQUEIRA et al., 2014).

O Decreto no. 5813 de 22 de junho de 2006 tinha como objetivo propiciar aos brasileiros o acesso às plantas medicinais através de práticas seguras. Essa atividade visava tornar de forma segura o desenvolvimento sustentável do país através da inserção das plantas medicinais e de fitoterápicos no âmbito do Sistema Único de Saúde (SUS) e do reconhecimento das práticas populares (BRASIL, 2009).

É importante que o professor relacione os saberes construídos na escola com o cotidiano do aluno, a fim de propiciar uma educação voltada para o contexto social em que está inserido (KRASILCHIK, 2016). Sendo assim, atividades que visem à construção de uma aprendizagem significativa possibilitam a ressignificação dos saberes do aluno, instigando-o a trabalhar os conhecimentos prévios com o objetivo de elaborar os conceitos que permeiam o âmbito científico (AUSUBEL, 1982). Nesse sentido, a Base Nacional Comum Curricular (BNCC), dispõe sobre competências e habilidades que espera de todos os alunos ao longo da escolaridade básica de modo que as atividades escolares devem estar relacionadas ao cotidiano dos alunos com o intuito de, a partir disso, promover uma educação de qualidade (BRASIL, 2018).

Quando a etnobotânica é trabalhada em sala de aula pelo professor, o qual busca valorizar os conhecimentos basais dos alunos, pode contribuir para a construção de uma aprendizagem significativa (SIQUEIRA, 2012). Por isso, o ensino de Biologia pode auxiliar na construção dessa aprendizagem, por meio de estratégias metodológicas que coloquem o aluno em uma perspectiva central do processo de ensino e aprendizagem (SIQUEIRA; PEREIRA, 2014).

Portanto, o presente trabalho teve como objetivo identificar os conhecimentos dos alunos da $3^{a}$ série do Ensino Médio de uma escola pública e privada em Floriano/PI, acerca da utilização de plantas medicinais empregadas para fins terapêuticos, assim como também, verificar de que forma esses saberes podem interferir na escolha desse recurso natural pelos alunos. 


\section{Metodologia}

\section{Área de estudo}

Este estudo foi desenvolvido no município de Floriano/Pl, encontra-se na Zona Fisiográfica do Médio Parnaíba, à $240 \mathrm{Km}$ da capital do Piauí, Teresina. Suas coordenadas geográficas são: 06 46' 01" S, 43 01' 22" W e 112 m de altitude em relação a Meridiano de Greenwich (IBGE, 2017). O trabalho foi desenvolvido entre o período de novembro de 2017 à fevereiro de 2018, com alunos do Ensino Médio de uma escola pública (EPU) da rede federal de ensino, e com alunos da escola privada (EPR), situadas ambas na cidade de Floriano-PI (Figura 1).

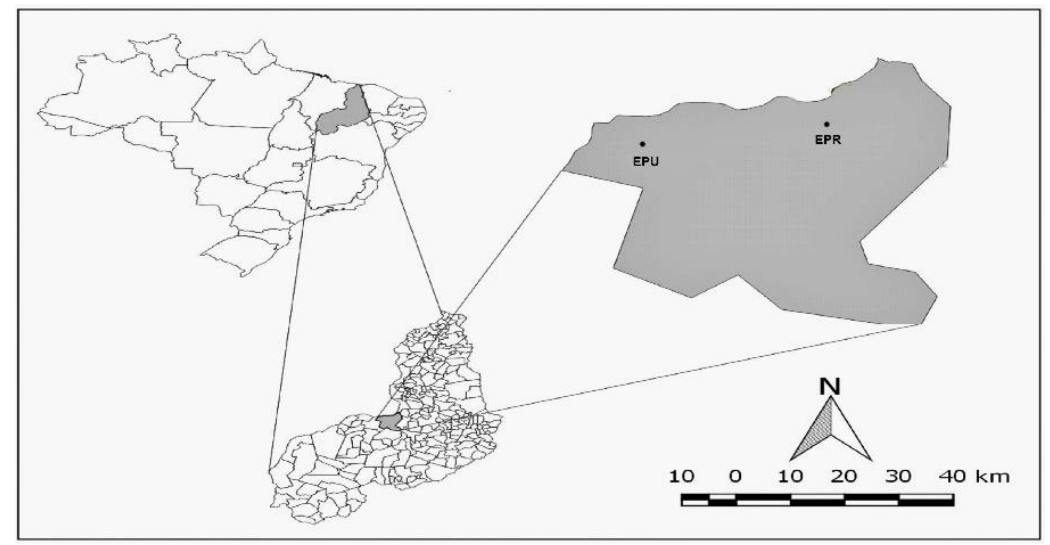

Figura 1. Localização das escolas pesquisadas na cidade de Floriano, Piauí, Brasil, 2018.

\section{Coleta e análise dos dados}

Trata-se de uma pesquisa epistemológica com abordagem quali-quantitativa (MARCONI; LAKATOS, 2017). Como instrumento de coleta de dados, utilizou-se um questionário com perguntas abertas e fechadas, aplicado com 100 (cem) alunos da $3^{a}$ série do Ensino Médio, sendo 50 (cinquenta) da rede pública e 50 (cinquenta) da rede privada de ensino. Esse instrumento tinha como objetivo conhecer as principais espécies das plantas utilizadas pelos alunos com propósito terapêutico; modo de administração; forma de preparo e consumo; principais benefícios para o organismo; conhecimento dos possíveis problemas que poderia acometer o indivíduo a nível celular.

Os dados foram analisados com base em proposição de categorias de análise, baseado nos trabalhos de Falcão e Barros (1999), Griffin et al. (2003), Silva e Neto (2004) e Carneiro e Silva (2007), com adaptações de Araújo, Freitas e Leite (2017). Essa categorização foi realizada tendo como parâmetro os pontos em comuns discutidos pelos pesquisados. A categoria 1 foi empregada quando o aluno não atribuia nenhum juízo de valor a questão, como por exemplo: não sei, resposta em branco, sem nexo ou completamente errada. Assim como, quando o aluno não conseguia por meio da resposta transcrita apresentar um conhecimento significativo sobre o assunto; na categoria 2, foi possível perceber o entendimento do aluno a respeito do tema, porém não há uma relação satisfatória com a literatura; já na categoria 3, as respostas foram consideradas satisfatórias sobre o tema e fizeram alusão aos conhecimentos científicos; e, por fim, na categoria 4, o aluno apresentou de forma sistemática e satisfatória domínio sobre o tema, além disso mostrou, através da 
sua resposta, uma discussão além do que foi questionado, apresentando um entendimento holístico sobre a temática em estudo.

Os resultados quantitativos foram interpretados com base em análises estatísticas. Para isso, utilizou-se o programa Statistical Package for the Social Sciences (SPSS) 23.0, no qual empregou os seguintes métodos: Teste-t, análise descritiva simples e a correlação bivariada por meio do coeficiente de Spearman, sendo que o valor de $\rho$ variando entre: 0.00 a 0.19 uma interação do tipo bem fraca; 0.20 a 0.39 fraca; 0.40 a 0.69 moderada; 0.70 a 0.89 forte; 0.90 a 1.00 do tipo muito forte, podendo ser do tipo positiva ou negativa, com ênfase na criação do flag para as correlações significantes, sendo ${ }^{\star} \rho<0,05 ;{ }^{* \star} \rho<0,01$ e ${ }^{* \star \star} \rho<0,001$.

\section{Resultados e Discussão}

Verificou-se que 52\% dos alunos da EPU eram do sexo masculino e 58\% do sexo feminino, com idade média de $\pm 17,2$ anos. Com relação aos alunos da EPR, evidenciou-se que $38 \%$ eram do sexo masculino e $62 \%$ do sexo feminino, com idade média de $\pm 17,2$ anos.

Buscou-se identificar se os alunos de ambas as escolas utilizavam as plantas medicinais. Verificou-se que $82 \%$ dos alunos da EPU e 92\% dos alunos da EPR faziam uso desse recurso natural. Uma pequena parcela em torno de 18\% da EPU e $8 \%$ da EPR não faziam uso das plantas medicinais para fins terapêuticos (Figura 2).

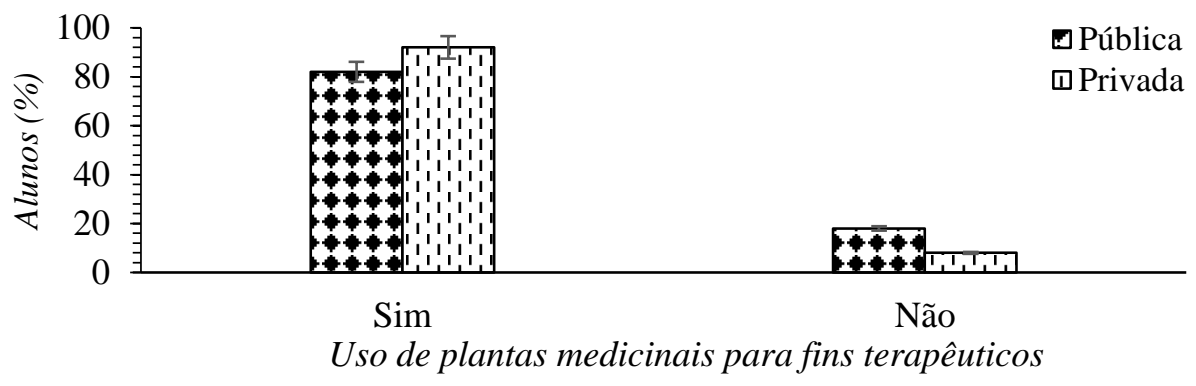

Figura 2. Utilização das plantas medicinais pelos alunos da 3a série do Ensino Médio da EPU e EPR, Floriano (PI)

Este resultado mostrou uma correlação significativa com a idade dos alunos da EPR $p<0,05$. O Teste-t evidenciou que, em média, os alunos da EPU utilizavam menos as plantas medicinas para fins terapêuticos quando comparados aos alunos da EPR (t (98) = 1,488; $p<0,05)$. Em estudo semelhante, que tinha como objetivo identificar os conhecimentos dos alunos da graduação da Universidade Estadual da Paraíba - UEPB, nos cursos de Letras, Ciências Agrárias e Agropecuária, observou-se que 75\% dos entrevistados utilizavam as plantas medicinais para fins terapêuticos, a fim de tratar ou mitigar alguns dos sintomas de determinadas doenças (NÓBREGA et al., 2017).

Assim, o cultivo de espécies medicinais, principalmente aquelas observadas nos quintais das moradias é uma prática recorrente por muitas famílias brasileiras. Em uma pesquisa realizada com 70 alunos do Ensino Médio do Colégio Estadual de Período Integral (CEPI) na cidade de Inhumas, Goiás, verificou-se que, $77 \%$ dos alunos também utilizavam as plantas medicinais com propósitos terapêuticos. Além disso, 59\% cultivavam algumas espécies nos quintais de suas próprias residências (SOUZA; LIMA; VALE, 2015). 
Em decorrência da utilização das plantas medicinais para fins terapêuticos pelos alunos de ambas as escolas pesquisadas, buscou-se saber as principais plantas que eram empregadas para esse fim, bem como, qual era a estrutura da planta utilizada com sua respectiva indicação terapêutica. As famílias de plantas medicinais com o maior número de espécies citadas pelos alunos da EPU foram Lamiaceae (23 citações), Rutaceae (11 citações), Verbenaceae (4 citações) e Fabaceae (4 citações), juntas reuniram 82\% das espécies citadas. Dá mesma forma, os alunos da EPR citaram as principais famílias: Lamiaceae (15 citações), Rutaceae (8 citações), Verbenaceae (5 citações), Fabaceae (3 citações), juntas reuniram 62\% das espécies citadas (Quadro 1).

Quadro 1. Plantas medicinais citadas pelos alunos de ambas as escolas, com sua respectiva família, nome científico, popular, estrutura utilizada, forma de preparo e indicações terapêuticas na perspectiva dos alunos da $3^{a}$ série do Ensino Médio da EPU e EPR, Floriano (PI).

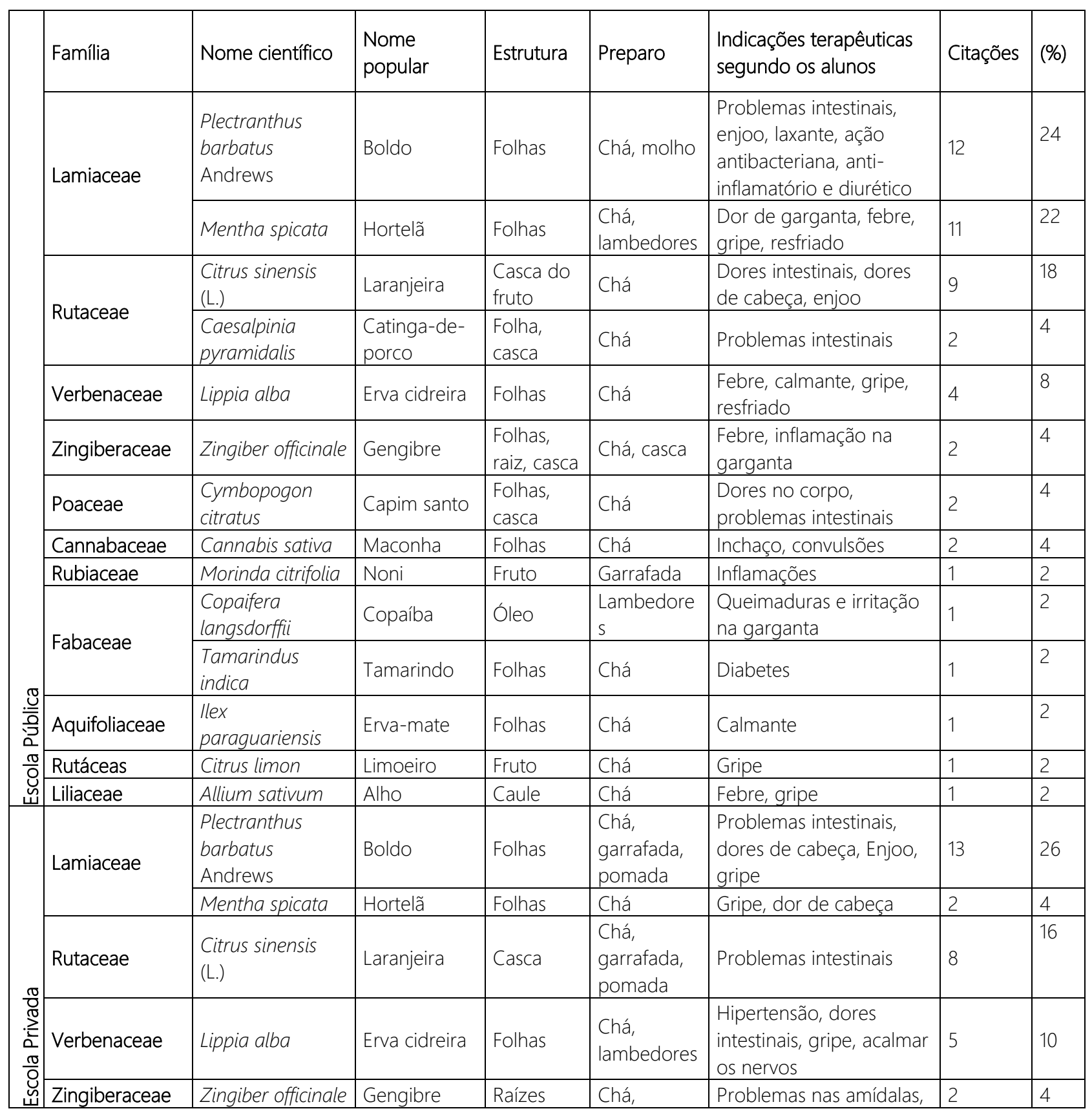




\begin{tabular}{|c|c|c|c|c|c|c|c|}
\hline & & & & \begin{tabular}{|l|} 
xarope/lam \\
bedores
\end{tabular} & $\begin{array}{l}\text { dores de cabeça, } \\
\text { intestinais }\end{array}$ & & \\
\hline Rubiaceae & Morinda citrifolia & Noni & Fruto & Fruto & Dores em geral & 2 & 4 \\
\hline Punicaceae & Punica granatum & Romã & Fruto & $\begin{array}{l}\text { Lambedore } \\
\text { s, in natura }\end{array}$ & Inflamação na garganta & 2 & 4 \\
\hline \multirow[t]{2}{*}{ Fabaceae } & $\begin{array}{l}\text { Caesalpinia } \\
\text { pyramidalis }\end{array}$ & $\begin{array}{l}\text { Catinga-de- } \\
\text { porco Pau- } \\
\text { de-rato }\end{array}$ & Casca & Chá & Problemas intestinais & 2 & 4 \\
\hline & $\begin{array}{l}\text { Peltophorum } \\
\text { dubium } \\
\end{array}$ & Faveira & Casca & $\begin{array}{l}\text { Xarope/lam } \\
\text { bedores }\end{array}$ & Problemas intestinais & 1 & 2 \\
\hline Moraceae & Castilla ulei & Inharé & Caule & Garrafada & $\begin{array}{l}\text { Melhora a circulação } \\
\text { sanguínea }\end{array}$ & 2 & 4 \\
\hline Malvaceae & $\begin{array}{l}\text { Hibiscus rosa- } \\
\text { sinensi }\end{array}$ & Hibisco & Casca & Chá & Diarreia & 1 & 2 \\
\hline Apiaceae & $\begin{array}{l}\text { Pimpinella } \\
\text { anisum }\end{array}$ & Erva doce & Sementes & Chá & Problemas intestinais & 1 & 2 \\
\hline Asteraceae & $\begin{array}{l}\text { Matricaria } \\
\text { chamomilla }\end{array}$ & Camomila & Folhas & Chá & Alivia o estresse e cólicas, & 1 & 2 \\
\hline Phytolaccaceae & Petivea alliacea & Tipí & Folhas & Chá & Cólicas & 1 & 2 \\
\hline Euphorbiaceae & $\begin{array}{l}\text { Euphorbia } \\
\text { tirucalli }\end{array}$ & $\begin{array}{l}\text { Cachorro } \\
\text { pelado }\end{array}$ & Secreção & Garrafada & Tratamento de câncer & 1 & 2 \\
\hline Liliaceae & Aloe vera & Babosa & Gel & Chá & Queimadura & 1 & 2 \\
\hline
\end{tabular}

O quadro 1 foi construído de forma similar a metodologia proposta por Mera et al. (2018). Foi exposto via imagens as principais plantas que são usadas para fins terapêuticos com sua previa catalogação seguindo a APG (Grupo de Filogenia das Angiospérmicas), a fim de que os alunos pudessem identificar as plantas de forma correta (CRONQUIST, 1988). A utilização de espécimes da família Lamiaceae também foi identificada em estudos similares (COSTA; MAYWORM, 2011; ALVES; POVH, 2013). Este dado pode ser explicado em decorrência da distribuição cosmopolita de suas espécies e o grau de importância que a população atribui aos seus principais representantes. Por isso, identificou-se o emprego dessas espécies em detrimento do seu alto valor terapêutico, além de serem ricos em óleos essenciais o que proporciona as propriedades aromáticas e medicinais a essas plantas (JUDD et al., 2009; ALVES; POVH, 2013; NETO et al., 2014; SANTOS et al., 2016).

A família Lamiaceae é considerada uma das mais comuns entre as plantas medicinais (GANDOLFO; HANAZAKI, 2011), tendo sido identificada como a mais citada pelos alunos de ambas as escolas. A segunda família mais citada foi a Rutaceae, tendo como os principais representantes a laranjeira e o limoeiro, considerados espécies cítricas de grande valor econômico para o país. Essa família concentra-se em torno de 150 gêneros e 1600 espécies, distribuídas por diversas regiões tropicais, com aproximadamente 29 gêneros e 189 espécies encontradas no Brasil. É bastante utilizada na medicina tradicional por suas propriedades terapêuticas, pois o gênero Citrus apresenta em sua estrutura cumarinas, flavonoides, óleos voláteis e pectinas cerebrais (CARVALHO et al., 2013).

Em estudo similar, identificou-se que dentre as plantas medicinais utilizadas, 27\% dos alunos consumiam o boldo (Plectranthus barbatus Andrews) em forma de chás (FRANCO; SOUZA, 2016). Um levantamento etnobotânico realizado com alunos do Ensino Médio, constatou-se que esses saberes vêm sendo repassados ao longo das gerações, sendo de pais para filhos, construídos através das tradições familiares, livros e, até mesmo, nas próprias relações interpessoais (MESSIAS et al., 2015). 
A utilização das plantas medicinais para fins terapêuticos vem sendo identificada ao longo da história. Por isso, buscou-se saber se os alunos fazem uso dessa prática. Dentre os alunos da EPU, 2\% afirmam nunca terem utilizado as plantas medicinais com esta finalidade, e 20\% o fazem frequentemente. Já os alunos da EPR, uma pequena amostra (4\%), afirmaram nunca terem utilizado as plantas com esse propósito terapêutico, e 18\% o fazem com frequência (Figura 3).

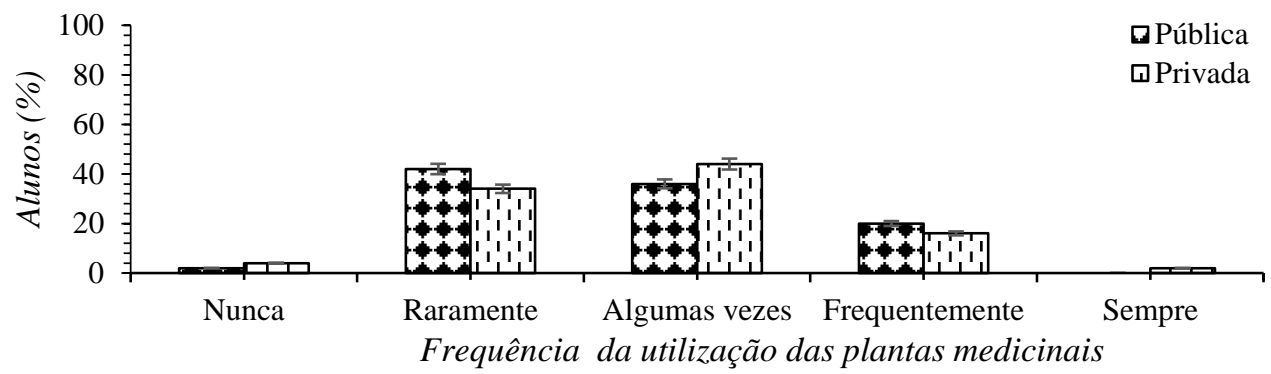

Figura 3. Frequência do uso de plantas medicinais para fins terapêuticos por alunos da $3^{a}$ série do Ensino Médio da EPU e EPR, Floriano (PI).

Identificou-se uma correlação significativa da frequência do uso com a possível troca de um fármaco por uma planta medicinal pelos alunos da EPU $p<0,05$ e na EPR $p<0,01$. $O$ Teste-t mostrou que os alunos da EPU, em média, utilizavam menos as plantas medicinais para fins terapêuticos em comparação aos alunos da EPR (t $(98)=0,243 ; p<0,05$ ).

O Brasil é considerado um país com uma rica biodiversidade, pois possui um grande potencial de exploração de seus recursos naturais. Com relação ao número de espécies, estima-se que tenha em torno de $20 \%$ do total presente no mundo (RODRIGUES, 2016). Por isso, cerca de $80 \%$ da população mundial utiliza as plantas medicinais no processo da atenção primária de saúde. Em um estudo investigativo realizado na cidade de Maringá, PR com 95 participantes do Programa de Educação para o Trabalho em Saúde (PET-Saúde) da Universidade Estadual de Maringá, 24,2\% dos entrevistados utilizavam frequentemente as plantas medicinais com o objetivo de tratar alguma doença ou enfermidade em decorrência de sua ampla distribuição (LOPES et al., 2015).

Verificou-se que, os alunos tinham a prática de substituir o fármaco por uma planta medicinal para o propósito terapêutico. Com relação aos alunos da EPU, 12\% afirmaram que nunca realizaram essa prática, $64 \%$ raramente e $24 \%$ frequentemente. Enquanto os alunos da EPR, 6\% afirmaram que nunca fizeram essa substituição, 54\% raramente, 40\% frequentemente e 10\% sempre realizaram essa troca (Figura 4).

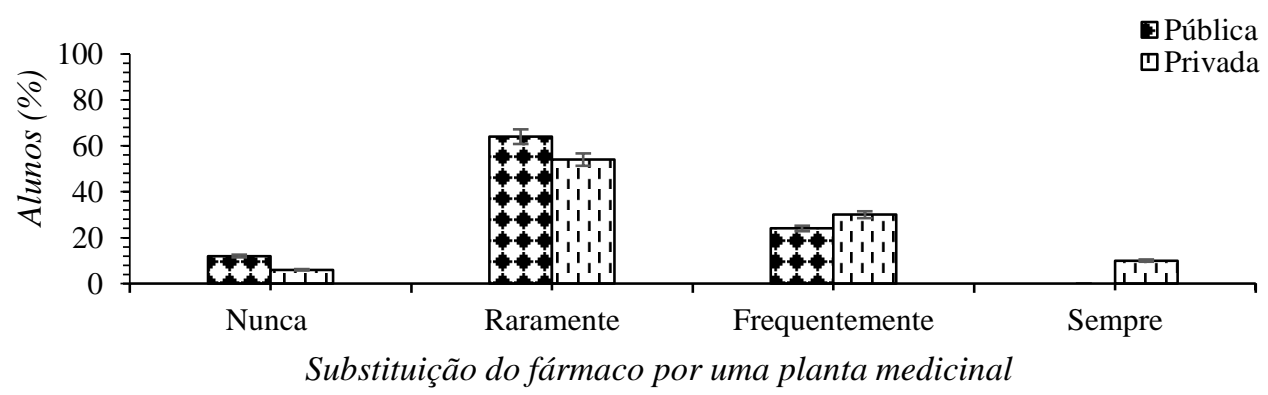

Figura 4. Possível substituição de um fármaco por uma planta medicinal segundo os alunos da $3^{a}$ série do Ensino Médio da EPU e EPR, Floriano (PI). 
Evidenciou-se que, houve uma correlação significativa entre a substituição de um fármaco com o sexo, idade e a frequência que utilizavam as plantas medicinais pelos alunos da EPU, ambas apresentaram $p<0,05$. Com relação aos alunos da EPR, essa variável está correlacionada com a frequência em que se utilizavam as plantas medicinais $p<0,01$. 0 Teste-t mostrou que, em média, os alunos da EPU raramente trocam o fármaco por uma planta medicinal em comparação aos alunos da EPR (t (98) = -2,346; $p<0,05$ ).

No trabalho desenvolvido por David et al. (2014), destacou-se a utilização de plantas medicinais por comunidades da zona rural no interior do Brasil, com o intuito de tratar determinadas doenças. A utilização dessas plantas em substituição a um fármaco, estava diretamente ligada à distância do atendimento médico que em muitas regiões ficam quase inacessível, ou até mesmo pelos elevados custos financeiros dos medicamentos.

Em decorrência da utilização das plantas medicinais por ambas as escolas, investigou a respeito se o consumo pode trazer algum problema ao organismo humano em virtude de sua administração. Com relação aos alunos da EPU, 32\% afirmaram que sim e uma expressiva parcela (68\%) relataram que não, pois não causaria nenhum problema. Para a EPR, poucos alunos (12\%) consideravam que essa prática poderiam trazer prejuízos ao indivíduo e 88\% acreditavam que não causava mal algum ao indivíduo (Figura 5).

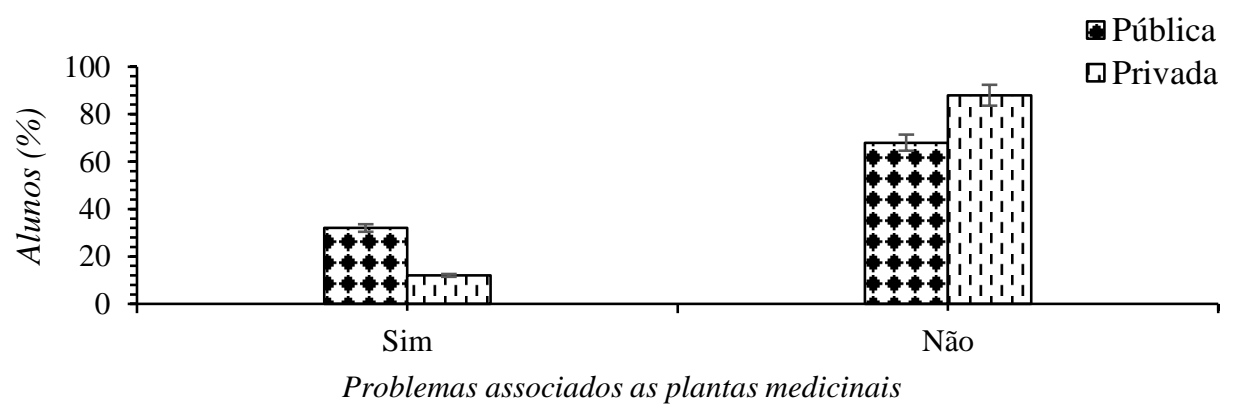

Figura 5. Possíveis problemas que as plantas medicinais podem ocasionar ao organismo humano, caso seja administrado de forma errada a luz das percepções dos alunos da $3^{a}$ série do Ensino Médio da EPU e EPR, Floriano (PI).

Através da correlação de Spearman, identificou-se que há duas correlações significativas, a primeira com a idade dos alunos da EPU $p<0,05$; e a segunda com os possíveis problemas na administração de chás $p<0,01$. A medida que na EPR esse resultado teve uma correlação significativa com os principais problemas em decorrência do consumo de chás de forma errada $p<0,01$. O Teste-t mostrou que, em média, os alunos da EPR afirmaram que esse consumo, muitas vezes, errado não pode trazer algum problema ao organismo humano em comparação a EPU (t (98) = -2,463; $p<0,05)$.

Nos últimos anos, vem se discutindo no âmbito científico a utilização de recursos naturais com propriedades farmacológicas, devido ao fato de ser mais acessível à população (SCHIAVO; SCHWAMBACH; COLET, 2017). No entanto, o consumo destas substâncias de forma demasiada, sem a real comprovação científica pode trazer riscos às células, especificamente durante o processo de divisão celular contribuindo para a formação de aberrações cromossômicas (ARAÚJO; FREITAS; LEITE, 2017; MELO et al., 2017).

A forma de preparo de algumas plantas medicinais é um processo importante para a manutenção de suas propriedades farmacológicas. Por isso, questionou-se aos alunos de ambas as escolas qual era a parte que eles mais utilizavam. Os alunos da EPU apresentaram 
em sua maioria as folhas (70\%) e a casca (22\%). Por outro lado, o resultado da EPR foi bem similar, em que as folhas apresentaram 58\% e casca 30\% (Figura 6).

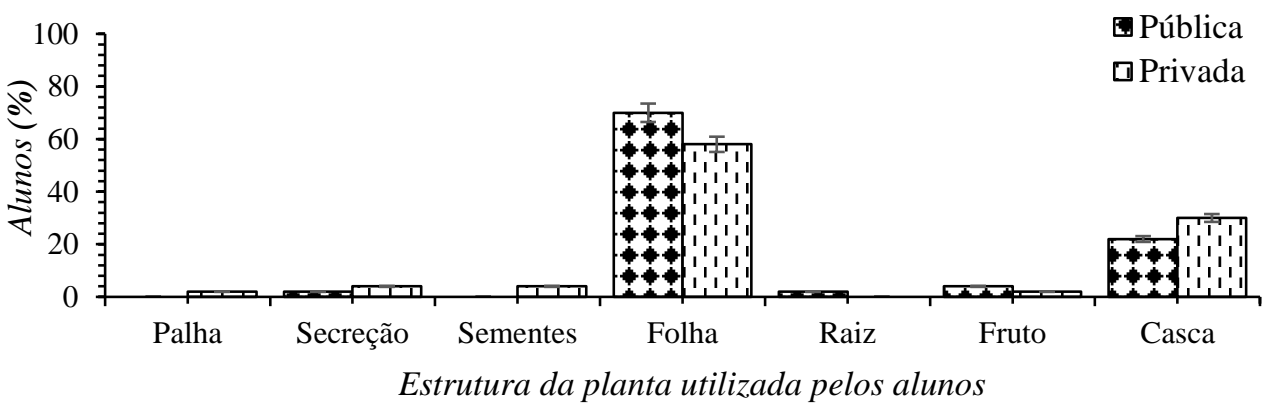

Figura 6. Partes das plantas medicinais utilizadas para fins terapêuticos pelos alunos da $3^{a}$ série do Ensino Médio da EPU e EPR, Floriano (PI).

Observou-se que este resultado apresentou uma correlação significativa com a idade dos alunos da EPU $p<0,05$. Já o Teste-t destacou que, em média, os alunos da EPU utilizavam mais algumas estruturas, como as folhas, do que os alunos da EPR (t (98) =0,208 $p<0,05)$.

Diferentes partes dos vegetais podem ser utilizadas, tais como: caule, raízes, flores, frutos e sementes podendo haver a presença de princípios bioativos (EGAMBERDIEVA et al., 2017). A utilização das folhas vem sendo identificadas, principalmente na preparação de remédios caseiros, isso em decorrência da maior disponibilidade do recurso foliar em todas as estações do ano (VÁSQUEZ; MENDONÇA; NODA, 2014). Uma das grandes vantagens em utilizar as folhas das plantas medicinais é a estrutura as quais possuem uma maior quantidade de princípios ativos, além de não prejudicarem a planta, pois a obtenção delas não implica na morte do espécime (GUERRA et al., 2010).

Em resultados análogos, percebeu-se que dentre as partes das plantas medicinais usada pela população, as folhas eram as mais utilizadas para este fim (CASSINO, 2010; GIRALDI; HANAZAKI, 2010; NETO et al., 2014; SANTOS et al., 2016). Assim sendo, estudos desta natureza realizado por Santos-Lima et al. (2016), mostraram através de um levantamento das plantas medicinais indicadas pelos índios da etnia Kantaruré, aldeia Baixa das Pedras com ação antiparasitária, que as folhas eram a parte mais usada por essa etnia em torno de 58\% como remédio caseiro.

O preparo das plantas medicinais é um processo de extrema relevância para a aquisição de seus benefícios. Desse modo, buscou-se identificar qual era a forma em que os alunos de ambas as escolas utilizavam. Constatou-se os alunos da EPU usavam mais as plantas em forma de chá (60\%), lambedores/xarope (20\%), garrafada (12\%), pomada (6\%) e in natura (2\%). Ao passo que os alunos da EPR utilizavam mais o preparo em forma de chá que a EPU (84\%), lambedores/xarope (8\%), molho (2\%), garrafada (2\%), pomada (2\%) (Figura 7).

Identificou-se que, há uma correlação significativa deste resultado com os conhecimentos elementares dos alunos da EPU discutido nas categorias de análise (figura 8) $p<0,05)$. Para o Teste-t, em média, os alunos da EPR utilizavam mais o chá como mecanismo de preparação das plantas medicinais do que os alunos da EPU (t (98) = -2,364; $p<0,05)$. 


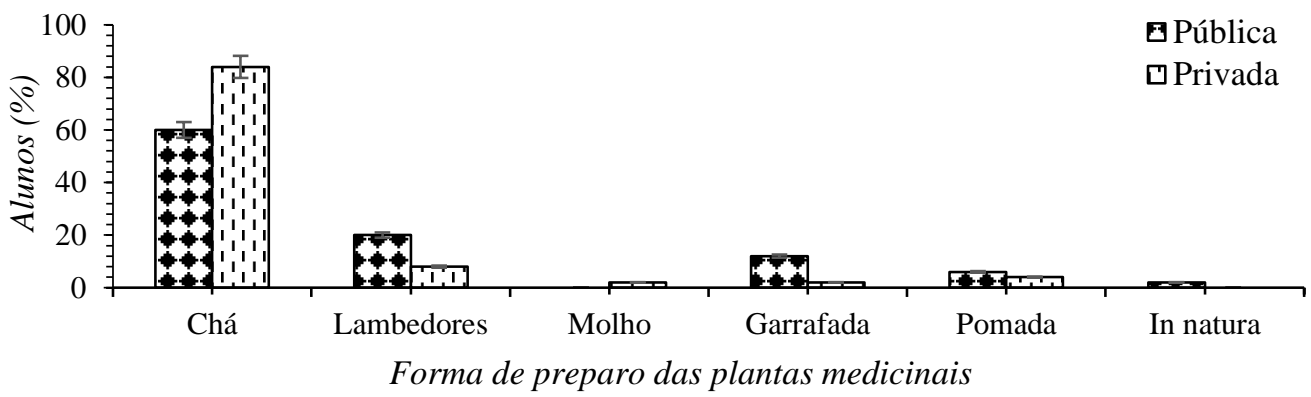

Figura 7. Forma como alunos da $3^{a}$ série do Ensino Médio da EPU e EPR - Floriano (PI), utilizavam as plantas medicinais.

Em estudo realizado com 21 moradores da zona rural do Municipio de Demerval Lobão, localizado no Estado do Piauí, observou-se que 58\% dos entrevistados preparavam as espécies medicinais cultivadas nos quintais de suas próprias residências na forma de chás (AGUIAR; BARROS, 2012). O chá é considerado a segunda bebida mais consumida pela população mundial, o qual além da capacidade aromática, pode possuir diversos benefícios à saúde humana, tais como: atividade antioxidante, antimutagênico, atua na prevenção de doenças cardiovasculares, auxilia na aceleração do metabolismo, além de possuir ação antibacteriana e antifúngica, entre outras (KUJAWSKA et al., 2016).

Quando questionados se o consumo de chás caseiros poderia causar algum dano ao organismo, os alunos da EPU afirmaram que não, pois é um recurso natural (76\%). Por outro lado, os alunos da EPR tiveram a mesma concepção em torno de (40\%) (figura 8).

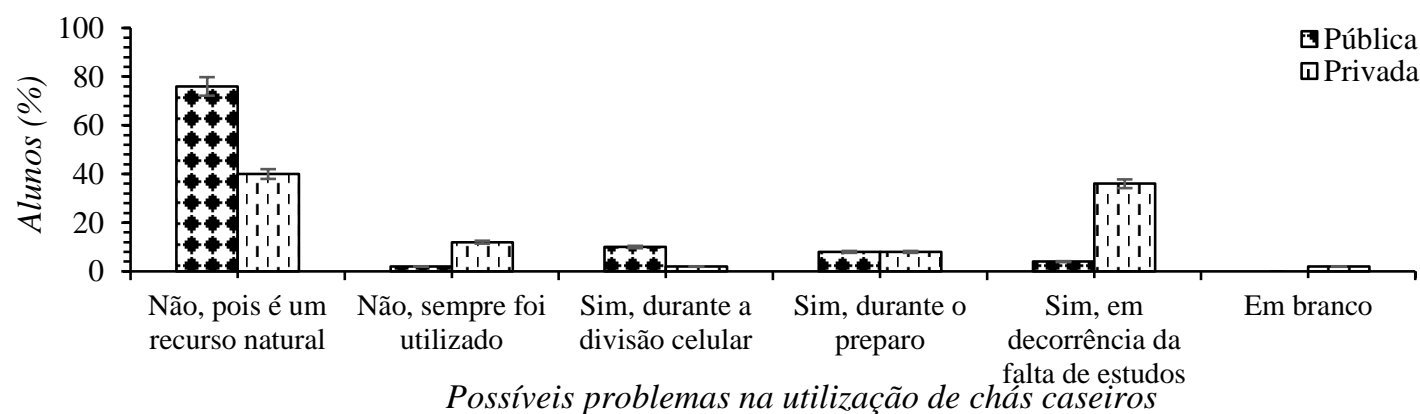

Figura 8. Percepções dos alunos da EPU e EPR sobre os possíveis problemas que a utilização de chás caseiros, a partir das plantas medicinais, podem causar ao organismo humano, caso seja mal administrado.

Evidenciou-se que há uma correlação significativa entre esse resultado e três varáveis no âmbito da EPU, a idade $p<0,05$; possíveis problemas que as plantas medicinais podem trazer $p<0,01$ e os conhecimentos elementares dos alunos discutidos nas categorias de análise (figura 8) $p<0,01$. Já na EPR, observou-se, também, que há existência da correlação significativa com os possíveis problemas que as plantas podem ocasionar $p<0,01$. O Teste-t mostrou que, em média, que os alunos da EPU consideravam que esse consumo de chás não trará nenhum problema ao organismo, em virtude de ser um recurso natural em comparação aos alunos da EPR (t (98) = 4,212; $p<0,01$ ).

As plantas medicinais são um recurso vegetal que durante anos vem sendo utilizadas pela população em geral. Esse conhecimento popular é utilizado, principalmente, pelas empresas farmacêuticas com o objetivo de encontrar novos princípios ativos, a fim de produzirem medicamentos capazes de tratar alguma doença. No entanto, deve-se ter 
cuidado com o consumo desses recursos, pois estudos toxicológicos mostram através de bioensaios preliminares que alguns dos representantes citados pelos alunos possuem substâncias cm atividades tóxicas e genotóxicas em decorrência de sua má administração ou uso (ZARDO et al., 2016).

Em decorrência dessas atividades, buscou-se saber se essas espécies utilizadas poderiam trazer algum problema a nível celular. A grande maioria dos alunos da EPU não soube responder (56\%), uma pequena parcela (16\%) responderam, porém, suas percepções não faziam alusão à literatura, alguns conseguiram explicar de forma satisfatória sobre esses problemas a nível celular (18\%), e uma pequena porcentagem em torno de (10\%) demonstraram terem um conhecimento além esperado, apresentando então um certo domínio da temática abordada. Já os alunos da EPR apresentaram as respostas semelhantes aos alunos da EPU, no entanto ainda há um certo desconhecimento dos principais riscos que podem se expor em detrimento do uso de determinadas plantas (Figura 9).

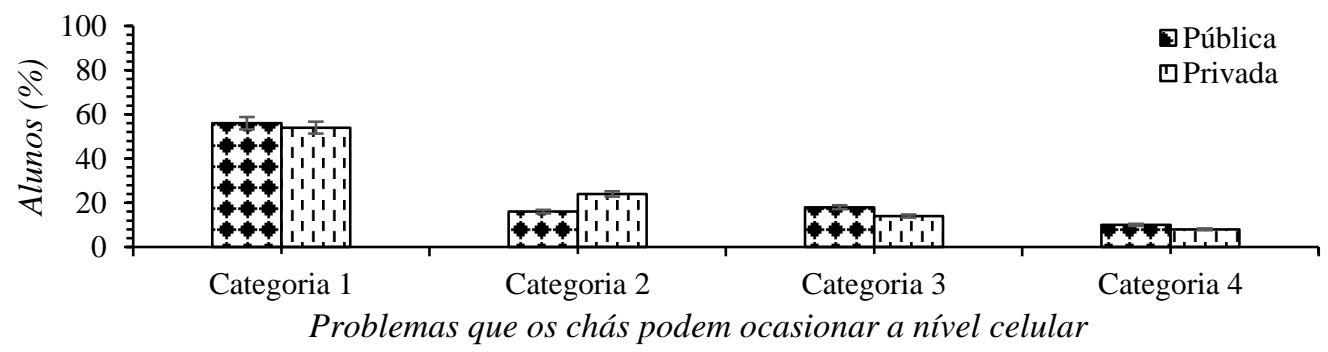

Figura 9. Categorização das respostas dos alunos da $3^{a}$ série do Ensino Médio da EPU e EPR, Floriano

(PI), sobre os problemas que o consumo de chás caseiros extraídos de plantas medicinais pode causar à saúde humana.

Evidenciou-se que, há uma correlação deste resultado com duas variáveis identificadas na EPU, sendo a primeira com a forma de preparo das plantas medicinais $p<0,05$ e a possibilidade de que os chás possam trazer algum problema ao organismo $p<0,01$. O Testet mostrou que, em média, os alunos da EPR apresentaram ter um conhecimento mais fragmentado em relação à temática que os alunos da EPU (t (98) = -0,293; p<0,05).

Em muitos tipos de chás são encontradas diversas substâncias bioativas. Em decorrência disso, muitas pessoas consomem essa bebida com vários propósitos. No entanto, podem estarem se expondo a agentes tóxicos, capaz de ser nocivos às células, pois conseguem interferir no metabolismo celular, principalmente no momento da divisão celular (SANTANA et al., 2016).

Os resultados demonstraram que os alunos, de ambas as escolas utilizam as plantas medicinais, sendo algumas vezes com finalidade terapêutica. No entanto, muitos deles, não tinha o conhecimento dos possíveis problemas que esse recurso natural pode ocasionar ao organismo humano, caso fosse administrado de forma errada (ARAÚJO; FREITAS; LEITE, 2017).

Isso pode estar relacionado com a fragmentação do conhecimento, pois esses saberes construídos ao logo da vivência dos alunos, muitas vezes não são aplicados no seu dia-adia (RIVAROSSA, 1999). Essa dicotomia deve ser superada, pois não pode haver essa dissociação entre os conhecimentos construídos na escola e no contexto social, pois os alunos devem ter condições de compreenderem os processos básicos que estão a sua volta e terem um posicionamento crítico formado (CAVAGLIER; MESSEDER, 2014). 


\section{Considerações Finais}

Identificou-se que os alunos de ambas as escolas na sua maioria utilizavam as plantas medicinais. As famílias mais citadas pelos alunos foram as Lamiaceae e Rutaceae. Dessa forma, verificou-se que os alunos da EPU e EPR tinham o conhecimento sobre as plantas medicinais, porém de forma fragmentada. Isso, poderá levá-los a utilizarem essas plantas sem associação com os riscos e/ou benefícios que elas podem propiciar.

Em ambas as escolas, os alunos não relacionaram as plantas com os problemas ao organismo. Raramente substituíam um fármaco por esse recurso natural. Constatou-se, ainda que a parte mais utilizada eram as folhas e a casca na forma de chá, sendo as folhas mais citada por eles. Além disso, a grande maioria dos alunos da EPU e EPR não tinha conhecimento dos possíveis riscos que as plantas medicinais poderiam ocasionar a nível celular em decorrência da administração e posologia dessa substância.

Por isso, é importante que os alunos utilizem o conhecimento etnobotânico a respeito das plantas medicinais. No entanto, devem ter cuidado com o uso excessivo, pois estudos toxicológicos evidenciaram atividades tóxicas e genotóxicas de alguns representantes dessas famílias. Portanto, há necessidade de estudos mais aprofundados com o objetivo de avaliar as principais propriedades biológicas dos espécimes encontrados neste estudo, a fim de propiciar uma maior segurança no consumo dessas plantas a esses estudantes.

\section{Referências}

AGUIAR, L. C. G. G.; BARROS, R. F. M. Plantas medicinais cultivadas em quintais de comunidades rurais no domínio do cerrado piauiense (Município de Demerval Lobão, Piauí, Brasil). Revista Brasileira de Plantas Medicinais, v. 14, n. 3, p. 419-434, 2012.

ALVES, G. S. P., POVH, J. P. Estudo etnobotânico de plantas medicinais na comunidade de Santa Rita, Ituiutaba - MG. Biotemas, v. 26, n. 3, p. 231-242, 2013.

ARAÚJO, M. S.; FREITAS, W. L. S.; LEITE, A. S. O estudo etnobotânico de plantas medicinais utilizadas com fins terapêuticos por alunos de uma escola pública estadual em Floriano, Piauí, Brasil. In: Congresso Internacional das Licenciaturas Cointer - PDVL, Natal: Anais... Natal: IFRN, 1-12, 2017,

AUSUBEL, D. P. A aprendizagem significativa: a teoria de David Ausubel. São Paulo: Moraes, 1982.

BRASIL. Ministério da Saúde. Programa Nacional de Plantas Medicinais e Fitoterápicos. Brasília, DF, 2009.

BRASIL. Ministério da Saúde. Agência Nacional de Vigilância Sanitária. RDC no 48 de 16 de março de 2004. Regulamento Técnico sobre Registro de Medicamentos Fitoterápicos. Diário Oficial da União. Brasília, DF, 2004.

BRASIL. Ministério da Educação. Base Nacional Nacional Comum Curricular: educar é à base. Brasília: Câmara, 2018.

CARNEIRO, S. P.; SILVA, J. O Teste Allium cepa no ensino de Biologia Celular: um estudo de caso com alunos da graduação. Revista Acta Scientiae, v. 9, n. 2, p. 122-130, 2007. 
CARVALHO, R. B. F. et al. Composição química e atividade anticolinesterásica de uma fração ativa do extrato de folhas de Citrus limon (L.). Burm. Química Nova, v. 36, n. 9, p. 1375-1379, 2013.

CASSINO, M. F. Estudo etnobotânico de plantas medicinais em comunidades de várzea do rio Solimões, Amazonas e aspectos farmacognósticos de Justicia pectoralis Jaca. forma mutuquinha (Acanthaceae). Dissertação (mestrado) - Universidade Federal do Amazonas, Manaus, Amazonas, 2010.

CAVAGLIER, M. C. S.; MESSEDER, J. C. Plantas Medicinais no Ensino de Química e Biologia: Propostas Interdisciplinares na Educação de Jovens e Adultos. Revista Brasileira De Pesquisa Em Educação em Ciências, v. 14, n. 1, p. 55-71, 2014.

COSTA, V. P.; MAYWORM, M. A. S. Plantas medicinais utilizadas pela comunidade do bairro dos Tenentes - município de Extrema, MG, Brasil. Revista Brasileira de Plantas Medicinais, v. 13, n. 3, p. 282-292, 2011.

CRONQUIST, A. The evolution and classification of flowering plants. $2^{\text {nd }}$. edition. New York Botanical Garden: Bronx, 1988.

DAVID, M. et al. Uso de plantas medicinais em comunidade escolar de Várzea Grande, Mato Grosso, Brasil. Biodiversidade, v. 13, n. 1, p. 38-50, 2014.

EGAMBERDIEVA, D. et al. Antimicrobial activity of medicinal plants correlates with the proportion of antagonistic endophytes. Frontiers in Microbiology, v. 8, n. 199, p. 1-11, 2017.

FRANCO, S. E. P.; SOUZA, A. C. R. Levantamento das plantas medicinais utilizadas por alunos do programa de ensino de jovens e adultos (EJA) no município de Porto Velho - RO. Saber Científico, v. 1, n. 1, p. 1-7, 2016.

EVERT, R. F.; EICHHORN, S. E. Biologia Vegetal. 8. ed. Rio de Janeiro: Guanabara Koogan, 2014.

FALCÃO, D.; DE BARROS, H. L. Estudo de impacto de uma visita a uma exposição de um museu de ciências. II Encontro Nacional de Pesquisa em Educação e Ciências, 1999. 11p.

GANDOLFO, E. S.; HANAZAKI, N. Etnobotânica e urbanização: connhecimento e utilização de plantas de resting pela comunidade nativa do distrito do Campeche (Florianópolis, SC). Acta Botanica Brasilica, v. 25, n. 1, p. 168-177, 2011.

GIRALDI, M.; HANAZAKI, N. Uso e conhecimento tradicional de plantas medicinais no Sertão do Ribeirão, Florianópolis, SC, Brasil. Acta Botanica Brasilica, v. 24, n. 1, p. 395-406, 2010.

GRIFFIN, V. et al. Identifying novel helix-loophelix genes in Caenorhabditis elegans through a classroom demonstration of functional genomics. Cell Biology Education, v. 2, n. 1, p. 51-62, 2003.

GUERRA, A. M. N. M. et al. Utilização de plantas medicinais pela comunidade rural Moacir Lucena, Apodi-RN. Bioscience Journal, v. 26, n. 3, p. 442-450, 2010.

IBGE. Instituto Brasileiro de Geografia e Estatistica. Diretoria de Pesquisas, Coordenação de População e Indicadores Sociais, Estimativas da população residente com data de referência $1{ }^{\circ}$ de julho de 2017. Brasília, DF, 2017. 
JUDD, W.S. et al. Sistemática vegetal: um enfoque filogenético. 3. ed. Porto Alegre: Artmed, 2009.

KUJAWSKA, M. et al. Protective effect of yellow tea extract on $\mathrm{N}$-nitrosodiethylamineinduced liver carcinogenesis. Pharmaceutical Biology, v. 3, n. 1, p. 1-10, 2016.

KRASILCHIK, M. Prática de ensino de Biologia. 4. ed. São Paulo: Edusp, 2016.

LARANJEIRA, D. B. S. et al. Plantas medicinais em quintais produtivos no semiárido baiano. Cadernos Macambira, v. 1, n. 2, p. 123-127, 2016.

LIMA, C. A. A. et al. A etnobotânica aplicada à úlcera gástrica e avaliação farmacológica de Solanum stipulaceum. Revista Acta Brasiliensis, v. 1, n. 1, p. 1-7, 2017.

LOPES, M. A. et al. Estudo das plantas medicinais, utilizadas pelos pacientes atendidos no programa "Estratégia saúde da família" em Maringá/PR/Brasil. Revista Brasileira de Plantas Medicinais, v. 17, n. 4, p. 702-706, 2015.

MACHADO, M. A. B. et al. Plantas medicinais, características e usos: um estudo no contexto da educação do campo. Facit Business and Technology Journal, v. 2, n. 1, p. 31-54, 2017.

MARCONI, M. A.; LAKATOS, E. M. Fundamentos de Metodologia Científica. 8. ed. São Paulo: Atlas, 2017.

MELO, C. R. et al. O uso de plantas medicinais para doenças parasitárias. Revista Acta Brasiliensis, v. 1, n. 1, p. 28-32, 2017.

MERE, J. C. E. et al. Conhecimento, percepção e ensino sobre plantas medicinais em duas escolas públicas no município de benjamin constant - AM. Experiências em Ensino de Ciências, v. 13, n. 2, p. 62-79, 2018.

MESSIAS, M. C. T. B. et al. Uso popular de plantas medicinais e perfil socioeconômico dos usuários: um estudo em área urbana em Ouro Preto, MG, Brasil. Revista brasileira de plantas medicinais, v. 17, n. 1, p. 76-104, 2015.

MONTEIRO, S. C.; BRANDELLI, C. L. C. Farmacobotânica: aspectos teóricos e aplicação. Porto Alegre: Artmed, 2017.

NASCIMENTO, C. S. et al. O uso de plantas medicinais na percepção dos estudantes, da escola Estadual Marisa Mariano, de Barra do Garças-MT. Revista Eletrônica da Univar, v. 1, n. 8, p. 1-5, 2012.

NETO, F. R. G. et al. Estudo Etnobotânico de plantas medicinais utilizadas pela Comunidade do Sisal no município de Catu, Bahia, Brasil. Revista Brasileira de Plantas Medicinais, v. 16, n. 4, p. 856-865, 2014.

RIVAROSSA, A. P. El área de ciencias naturales: concepciones epistemológicas y diálogopedagógico. Argentina: Asociación de Docentes de Ciencias Biológicas de la Argentina, 1999.

NÓBREGA, J. S. et al. Avaliação do conhecimento etnobotânico e popular sobre o uso de plantas medicinais junto a alunos de graduação. Revista Brasileira de Gestão Ambiental, v. 11, n. 1, p. 7-13, 2017 
RODRIGUES, W. Competitividade e mudança institucional na cadeia produtiva de plantas medicinais no Brasil. Interações, v. 17, n. 2, p. 267-277, 2016.

SANTANA, G. M. et al. Antimitotic and antimutagenic action of the Hymenaea stigonocarpa bark on dividing cells. Brazilian Journal of Biology, v. 76, n. 2, p. 520-525, 2016.

SANTOS, A. B. N. et al. Plantas medicinais conhecidas na zona urbana de Cajueiro da Praia, Piauí, Nordeste do Brasil. Revista Brasileira de Plantas Medicinais, v. 18, n. 2, p. 442-450, 2016.

SANTOS-LIMA, T. M. et al. Plantas medicinais com ação antiparasitária: conhecimento tradicional na etnia Kantaruré, aldeia Baixa das Pedras, Bahia, Brasil. Revista Brasileira de Plantas Medicinais, v. 18, n. 1, p. 240-247, 2016.

SCHIAVO, M.; SCHWAMBACH, K. H.; COLET, C. F. Conhecimento sobre plantas medicinais e fitoterápicos de agentes comunitários de saúde de ljuí/RS. Revista de Pesquisa: Cuidado é Fundamental Online, v. 9, n. 1, p. 57-63, 2017.

SILVA, J; NETO, A. A. DNA \& Ambiente: uso de Ensaio Cometa como Ferramenta para Discussão Interdisciplinar de Lesão e Reparo do DNA na Pós Graduação em Ensino de Ciências. IV ENPEC. Bauru, SP: 2004. 13p.

SIQUEIRA, B. P.; PEREIRA, S. M. Abordagem etnobotânica no ensino de Biologia. Revista Eletrônica Mestrado em Educação Ambiental, v. 31, n. 2, 247-260, 2014.

SIQUEIRA, B. P. et al. Estudo etnobotânico de plantas medicinais utilizadas pela população atentida no "programa saúde da família" no município de juvenília, Minas Gerais. Revista Brasileira de Pesquisa em Ciências da Saúde, v. 1, n. 2, p. 39-45, 2014.

SIQUEIRA, B. P. Etnobiología en la educación básica. Revista de Educación en Biología, v. 15, 2, p. 12-19, 2012.

SOUZA, V. A.; LIMA, D. C. S.; VALE, C. R. Avaliação do conhecimento etnobotânico de plantas medicinais pelos alunos do ensino médio da cidade de Inhumas, Goiás. Revista Eletrônica de Educação da Faculdade Araguaia, v. 8, n. 8, p. 13-30, 2015.

TAIZ, L.; ZEIGER, E. Fisiologia Vegetal. 5. ed. Porto Alegre: Artmed, 2013.

VÁSQUEZ, S. P. F.; MENDONÇA, M. S.; NODA, S. N. Etnobotânica de plantas medicinais em comunidades ribeirinhas do Município de Manacapuru, Amazonas, Brasil. Acta Amazonica, v. 44, n. 4, p. 457-472, 2014.

ZARDO, A. et al. Levantamento de informações etnobotânicas, etnofarmacológicas e farmacológicas registradas na literatura sobre Tropaeolum majus L. (Chaguinha). Arquivo de Ciencia e Saúde UNIPAR, v. 20, n. 3, p. 195-198, 2016. 